\title{
Early Reading and Writing by Using the Manakok Game as a Manifestation of Basic Literacy
}

\author{
Chandra $^{1}$, Rahman ${ }^{2}$, N T Hartati ${ }^{3}$, A Kharisma ${ }^{4}$, M Fauziah $^{5}$, R Wismaliya ${ }^{6}$ \\ $\left\{{ }^{1}\right.$ chandra@fip.unp.ac.id, ${ }^{2}$ rahmanprofupi@upi.edu, ${ }^{3}$ tatat@upi.edu, ${ }^{4}$ annisakharismaupi@upi.edu, \\ ${ }^{5}$ kfauziah19@upi.edu, ${ }^{6}$ risawismaliya@upi.edu \} \\ 1,2,3,4,6 Universitas Pendidikan Indonesia Bandung, ${ }^{5}$ STKIP Syekh Manshur Pandeglang, \\ Indonesia
}

\begin{abstract}
Basic literacy was needed in the digital era. Given that low-class students are preoccupied with technology, it is feared that they do not recognize the Minangkabau children's game culture, one of which is the game manakok. While on the other hand, technology was increasingly making students' egocentric higher. Bringing the alpha generation closer to the culture of the manakok game in West Sumatra to succeed in the early reading and writing learning is the aim of this study. This research was conducted with literature studies. The results of the study show the emergence of the view that the manakok game as one of the cultures of Minangkabau children is assumed to be able to deliver early reading and writing learning in realizing basic literacy. Early reading and writing learning by using manakok games can be one of the new views in the world of education that learning can be realized with local wisdom. Manakok games can also build social attitudes among students by realizing familiarity in the game process. Although most students do not recognize the manakok game, familiarizing students with the culture of local wisdom is still better than the technological sophistication that shapes the ego slump.
\end{abstract}

Keywords: Early Reading and Writing, Manakok Game, Basic Literacy

\section{INTRODUCTION}

Technology in the industrial revolution era 4.0 developed very fast and very close to children. In supporting the compatibility between knowledge and technology, students need to be faced with basic literacy [1]. Basic literacy is the initial ability that underlies the true ability to read and write [2]. Basic literacy can be taught in the learning process in the lower class through the process of learning to early reading and writing [3].

Learning to early reading and writing is an important part that is inseparable learning in the lower class [4]. Both of these skills are the basis for achieving other skills success. Therefore, learning early reading and writing skills requires special attention from the teacher. Early reading and writing examine reading skills and writing skills in the low-grade focus in firstgrade elementary school [5]. Early reading skills are more oriented towards basic level reading skills, namely literacy skills [6]. Whereas initial writing skills are not much different from the initial reading skills. At the basic level, writing learning is more oriented to mechanical skills, 
namely how the techniques used in enforcing the functions of the stationery form readable writing [7].

Students are trained to be able to write or be similar to the skill of painting or drawing written symbols which, if combined in a structure, become meaningful symbols [8]-[10]. Besides, the learning of Early reading and writing skills should condition learning by visualizing letters correctly, directing students to listen carefully, and pronounce clearly [11], [12]. To achieve more maximal results, it can be done by directing students to imitate various forms of letters with movements of the body. Furthermore, with the basic skills of early reading and writing, students are gradually directed to the skill of understanding and pouring ideas, thoughts, and feelings into written language forms through written symbols they have mastered [13], [14]. It needs to be realized that to create an effective learning process early reading and writing skills that are not only immediately utilize the teacher's ability to teach. The use of learning methods is also a support in the learning process of early reading and writing. One method in question is the method of playing [15], [16].

Based on the results of the preliminary analysis carried out that in the process of learning to early reading and writing in rural elementary schools still tend to be monotonous. Learning was rarely presented with interesting game variations. The effect was that students often forget the letters they have learned because they do not know the various types of letters with certainty. Students tend to be passive in learning, so learning was seen only one-way communication, namely from teacher to students. Some teachers still have the view that playing only makes students noisy. These various phenomena must be overcome by beginning to give a view to the teacher about his perspective on the game. While on the side of the learning process it should be presented interestingly following student learning styles and hobbies of low-grade elementary students who tend to play. An interesting game is expressed in the learning process, which is a game that elevates local wisdom.

One game that raises local wisdom that can be associated with learning to early reading and writing was a game that develops in the environment of rural children in West Sumatra precisely in the Padang city. The game involves children aged 5-8 years. The playing game was done by writing certain letters on a friend's back and asking friends to guess the letters written on their backs. This game was assumed to be suitable to support early reading and writing learning which has a side of writing and reading in the process of implementation.

\section{RESEARCH METHOD}

The material was the game of playing a part of the local wisdom of West Sumatra as a strategy for learning to early reading and writing on basic literacy in the lower classes. The research method that was carried out in the analysis of literature review and field studies with the type of qualitative research carried out, namely Grounded Research. The research was carried out by beginning with literature analysis activities so that there was a process of constructing theory or categorization through analysis and the process of abstracting research findings. Next, reconstructing, interpreting, and interpreting the results of the study based on the conceptualization of the community used as the subject of the study. The qualitative research procedure using the grounded theory method consists of several stages: (1) the stage of problem formulation, (2) the stage of using theoretical studies (if necessary), (3) the stage of data collection and delivery, (4) the data analysis stage, and (5) inference or report writing stage [17]. The research data was collected through observation, interviews, and documentation studies. Interviews were conducted on West Sumatra cultural experts, community leaders, and actors in the game, namely children who live in the Padang city. 


\section{RESULTS AND DISCUSSION}

\subsection{Results of Analysis of Literature Studies About Early Reading and Writing}

Students are taught to read aloud syllables, words, labels, and simple sentences [18], [19]. Students are also trained to read voices (fluently) simple sentences consisting of 3-5 words with attention to pronunciation and correct intonation, pause (to stop, inhale): long or short pauses, giving emphasis to certain words according to the context, and starting identifying keywords from rather long readings [20]. The target of early reading learning is more directed at the ability to "literate" with the focus of teaching directed at technical reading skills [21].

Students can read and understand short texts by reading fluently (voicing) and reading aloud a few simple sentences [21], [22]. Reading the beginning that will be done is to get used to the right attitude, read aloud, read voices (fluently), and read the fragments [20], [23]. Students are accustomed to having the right attitude in reading, namely showing the correct sitting position, adjusting the distance between the eyes and the object must be right $(30 \mathrm{~cm})$, holding the object correctly, and opening the book in the right order [24]-[26].

Writing skills in the lower class require students to be able to write several sentences themselves with loose letters and connecting letters, write sentences dictated by the teacher, and write neatly using connecting letters by paying attention to the habit of correct writing attitude (holding and using stationery), copying and thicken, transcribe, write the beginning, write a few sentences with connecting letters, write sentences dictated by the teacher, and write with connecting letters [27]-[29]. The expected learning outcomes of the initial writing skills are that students behave correctly in writing dashed lines, straight lines, curved lines, circles, and letters forming lines that can be done by moving the index finger to make various shapes of lines and circles and holding the stationery and use it correctly [30]. Students can copy and thicken various forms of images, circles, and letters [31]. Students can copy or copy letters, words, or sentences from the book or the blackboard correctly [29]. Students can write letters, words, and simple sentences correctly and can be read by others [14], [15], [28].

\subsection{Results of Analysis of Literature Studies About Basic Literacy}

Basic literacy is the ability to listen, speak, read, write, and count concerning analytical skills to calculate, perceive, communicate, and describe information based on personal understanding and conclusions [1], [8], [32]. Basic literacy components include phonemic awareness, concepts of writing and stories, reading styles, and literacy as socio-cultural activities [2], [26], [33]. Basic literacy ability is the capacity to name letters and write them down, spell simple words, recognize letters and signs around, identify books from the title and carry out activities related to books [1], [2]. Literacy skills of preschoolers can be grouped into 6 types, namely the skill of telling, motivation to read writing, vocabulary, the sound of letters, knowledge of letters, and awareness of writing [34], [35]. There are three basic literacy skills, namely: print knowledge, emergent writing, and reading interest [8], [32].

\subsection{The Results of Observations, Interviews, And Study Documentation About the Game Manakok}

The results of research conducted based on observations, interviews, and study documentation of researchers on children who did the manakok game, it was found that children aged 6-7 years tended to play by writing certain letters on the backs of their friends. A friend 
who guesses foaming concentrates by feeling the letters formed by the fingers of a friend on his back. The child who guesses tries to feel the direction of the curve of the fingertip on his back. The tendency of students to guess the letters being tested. When playing words or playing games about words, children begin to doubt their guesses. Children tend to ask their friends again. In addition to asking for a birthday, there is also a child who asks for the movement of his friend's fingers that are scratched on his back to be easy to guess. If the writing movement on the back is done quickly, it tends to be the answer given by the friend who guessed wrong. While slow finger movements tend to be the right answer.

Based on the findings of research conducted in grade 1 elementary school, precisely in children aged 6-7 years about the role of the manalok game in the process of learning to read and write early, the success of basic literacy in the lower classes shows that playing manakok is considered suitable as a strategy in the reading learning process and writing starters for the success of basic literacy.

The ability to read early is more oriented to basic reading skills, namely literacy [11], [36]. That is, children can change and recite written symbols into meaningful sounds [37]-[39]. Found students' literate with letters written on their backs. At this stage, children can recite the letters of letters they read without being followed by an understanding of the symbols of the sounds of the symbol [20]-[22].

Early writing learning is more oriented to mechanical abilities [14], [27], [29]. Children are trained to be able to write (similar to the ability to paint or draw) written symbols which, if combined in a structure, become meaningful symbols [15], [28], [31]. It was found that students showed mechanical properties with letters written on the backs of their friends. Furthermore, with this basic ability, children are slowly being led to the ability to write further by expressing ideas, thoughts, feelings, into written language through written writing symbols that they have mastered [41]. This is true writing ability.

Basic literacy underlies the true ability to read and write [2], [40]. It seems like it was tested by students in the game that one student wrote and the other readers. Basic literacy consists of nine components, namely language, rules/conditions/habits, knowledge of letters, awareness of elements of language, compatibility of phonemes, emergent reading, emergent writing, motivation, and cognitive skills [1]-[3], [32], [33]. The basic literacy that is applied in learning to read and write early through manakok games is considered very suitable to support students' active learning and is fun and makes it easier for students to recognize and memorize letters and words written and read.

\section{CONCLUSIONS}

Based on the findings of the research and discussion, it can be concluded that a new theory that is related to the learning process is produced, namely playing manakok as a form of local wisdom of the people of Padang city can be used as a new strategy in learning to read and write the beginning to succeed in basic literacy.

\section{REFERENCES}

[1] W. E. Blanton et al., "Rethinking Middle School Reading Instruction : A Basic Literacy Activity," vol. 2711, 2007.

[2] T. Inoue, G. K. Georgiou, R. Parrila, and J. R. Kirby, "Examining an Extended Home Literacy Model: The Mediating Roles of Emergent Literacy Skills and Reading Fluency," Sci. Stud. Read., vol. 00, no. 00, pp. 1-16, 2018. 
[3] Y. Chang and P. Monaghan, "Quantity and Diversity of Preliteracy Language Exposure Both Affect Literacy Development : Evidence from a Computational Model of Reading Quantity and Diversity of Preliteracy Language Exposure Both Affect Literacy Development : Evidence from a Computatio," Sci. Stud. Read., vol. 23, no. 3, pp. 235253, 2019.

[4] Chandra, Mayarnimar, and M. Habibi, "Keterampilan Membaca dan Menulis Permulaan Menggunakan Model VARK untuk Siswa Sekolah Dasar," J. Inov. Pendidik. dan Pembelajaran Sekol. Dasar, vol. 2, no. 1, pp. 72-80, 2018.

[5] M. Van Den Boer and P. F. De Jong, "Stability of Visual Attention Span Performance and Its Relation With Reading Over Time," Sci. Stud. Read., vol. 22, no. 5, pp. 434441, 2018.

[6] L. J. Van Den Bosch, E. Segers, and L. Verhoeven, "The Role of Linguistic Diversity in the Prediction of Early Reading Comprehension : A Quantile Regression Approach," Sci. Stud. Read., vol. 23, no. 3, pp. 203-219, 2019.

[7] P. T. Daniels and D. L. Share, "Writing System Variation and Its Consequences for Reading and Dyslexia," Sci. Stud. Read., vol. 22, no. 1, pp. 101-116, 2018.

[8] J. L. Below, C. H. Skinner, J. Y. Fearrington, and C. A. Sorrell, "Gender Differences in Early Literacy: Analysis of Kindergarten through Fifth-Grade Dynamic Indicators of Basic Early Literacy Skills Probes,” School Psych. Rev., vol. 39, no. 2, pp. 240-257, 2010 .

[9] S. Han and J.-A. Shin, "Teaching Google search techniques in an L2 academic writing context," Lang. Learn. Technol., vol. 21, no. 3, pp. 172-194, 2017.

[10] I. Elgort, "Blog posts and traditional assignments by first- and second-language writers," Lang. Learn. Technol., vol. 21, no. 2, pp. 52-72, 2017.

[11] A. M. Elleman, L. M. Steacy, and D. L. Compton, "The Role of Statistical Learning in Word Reading and Spelling Development : More Questions Than Answers," Sci. Stud. Read., vol. 23, no. 1, pp. 1-7, 2019.

[12] R. Dzekoe, "Computer-based multimodal composing activities, self-revision, and L2 acquisition through writing," Lang. Learn. Technol., vol. 21, no. 2, pp. 73-95, 2017.

[13] A. Shahaeian, C. Wang, E. Tucker-drob, V. Geiger, G. Bus, and L. J. Harrison, "Early Shared Reading, Socioeconomic Status, and Children's Cognitive and School Competencies : Six Years of Longitudinal Evidence," Sci. Stud. Read., vol. 22, no. 6, pp. 485-502, 2018.

[14] M. Li and W. Zhu, "Explaining dynamic interactions in wiki-based collaborative writing," Lang. Learn. Technol., vol. 21, no. 2, pp. 96-120, 2017.

[15] M. Mirzaee and B. Yaqubi, "A conversation analysis of the function of silence in writing conferences," Iran. J. Lang. Teach. Res., vol. 4, no. 2, pp. 69-86, 2016.

[16] L. M. Steacy et al., "Development and prediction of context-dependent vowel pronunciation in elementary readers," Sci. Stud. Read., vol. 00, no. 00, pp. 1-15, 2018.

[17] I. G. A. N. Budiasih, "METODE GROUNDED THEORY DALAM RISET KUALITATIF," J. Ilm. Akunt. dan Bisnis, vol. 9, no. 1, 2014.

[18] K. C. Tsujimoto et al., "Causal Attribution Profiles as a Function of Reading Skills , Hyperactivity, and Inattention," Sci. Stud. Read., vol. 00, no. 00, pp. 1-19, 2018.

[19] T. Turunen, N. Kiuru, E. Poskiparta, P. Niemi, and J. Nurmi, "Word Reading Skills and Externalizing and Internalizing Problems from Grade 1 to Grade 2 - Developmental Trajectories and Bullying Involvement in Grade 3," Sci. Stud. Read., vol. 23, no. 2, pp. 161-177, 2019.

[20] M. Vandermosten, J. Wouters, P. Ghesquière, and N. Golestani, "Statistical Learning 
of Speech Sounds in Dyslexic and Typical Reading Children," Sci. Stud. Read., vol. 00, no. 00, pp. 1-12, 2018.

[21] E. Van Wingerden, E. Segers, H. Van Balkom, and L. Verhoeven, "Cognitive Constraints on the Simple View of Reading: A Longitudinal Study in Children With Intellectual Disabilities," Sci. Stud. Read., vol. 22, no. 4, pp. 321-334, 2018.

[22] J. Zhao, T. Li, M. A. Elliott, and J. G. Rueckl, "Statistical and Cooperative Learning in Reading: An Artificial Orthography Learning Study," Sci. Stud. Read., vol. 00, no. 00, pp. 1-18, 2017.

[23] X. Schmalz, K. Moll, C. Mulatti, and G. Schulte-körne, "Is Statistical Learning Ability Related to Reading Ability, and if so, Why?," Sci. Stud. Read., vol. 00, no. 00, pp. 113, 2018.

[24] O. M. Sawi and J. Rueckl, "Reading and the neurocognitive bases of statistical learning," Sci. Stud. Read., vol. 00, no. 00, pp. 1-16, 2018.

[25] R. Savage, G. Georgiou, R. Parrila, and K. Maiorino, "Preventative Reading Interventions Teaching Direct Mapping of Graphemes in Texts and Set-for- Variability Aid At-Risk Learners," Sci. Stud. Read., vol. 00, no. 00, pp. 1-23, 2018.

[26] M. Rossi, S. Martin-chang, and G. Ouellette, "Exploring the Space Between Good and Poor Spelling : Orthographic Quality and Reading Speed," Sci. Stud. Read., vol. 00, no. 00, pp. 1-10, 2018.

[27] H. Marashi and P. Tahan-Shizari, "Using convergent and divergent tasks to improve writing and language learning motivation," Iran. J. Lang. Teach. Res., vol. 3, no. 1, pp. 99-117, 2015.

[28] M. Tok, "Examining pre-service teacher views on the implementation of screen-based writing instruction," Int. Electron. J. Elem. Educ., vol. 7, no. 2, pp. 235-252, 2015.

[29] S. E. Sulak, "Investigation of Writing Habits of Primary," Int. Electron. J. Elem. Educ., vol. 10, no. 4, pp. 497-504, 2018.

[30] P. Bulut, "The effect of primary school students' writing attitudes and writing selfefficacy beliefs on their summary writing achievement," Int. Electron. J. Elem. Educ., vol. 10 , no. 2, pp. 281-285, 2017.

[31] A. Yamac and M. Ulusoy, "The Effect of Digital Storytelling in Improving the Third Graders 'Writing Skills *," Int. Electron. J. Elem. Educ., vol. 9, no. September, pp. 5986, 2016.

[32] J. Elliott, S. W. Lee, and N. Tollefson, "A Reliability and Validity Study of Dynamic Indicators of Basic Early Literacy Skills-Modified," School Psych. Rev., vol. 30, no. 1, 2001.

[33] C. A. Perfetti, J. Van Dyke, and L. Hart, "The psycholinguistics of basic literacy," in Applied Linguistics, 2001, vol. 21, pp. 127-151.

[34] Muhammadi, Taufina, and Chandra, "LITERASI MEMBACA UNTUK MEMANTAPKAN NILAI SOSIAL SISWA SD,” LITERA, vol. 17, no. 2, pp. 202-212, 2018.

[35] Taufina and Chandra, "Developing the Big Questions and Bookmark Organizers (BQBO) Strategy-Based Reading Literacy Learning Materials in the 4th Grade of Elementary School," Int. Conf. Sci. Educ. Teach., vol. 118, no. 5, pp. 857-864, 2017.

[36] Z. Qi, Y. S. Araujo, W. C. Georgan, J. D. E. Gabrieli, and J. Arciuli, "Hearing Matters More Than Seeing: A Cross- Modality Study of Statistical Learning and Reading Ability," Sci. Stud. Read., vol. 00, no. 00, pp. 1-15, 2018.

[37] C. Mimeau, J. Ricketts, and S. H. Deacon, "The role of orthographic and semantic learning in word reading and reading comprehension," Sci. Stud. Read., vol. 00, no. 00, 
pp. 1-17, 2018.

[38] K. Landerl et al., "Phonological Awareness and Rapid Automatized Naming as Longitudinal Predictors of Reading in Five Alphabetic Orthographies with Varying Degrees of Consistency," Sci. Stud. Read., vol. 23, no. 3, pp. 220-234, 2019.

[39] S. W. Van Der Kleij, M. A. Groen, E. Segers, and L. Verhoeven, "Sequential Implicit Learning Ability Predicts Growth in Reading Skills in Typical Readers and Children with Dyslexia," Sci. Stud. Read., vol. 23, no. 1, pp. 77-88, 2019.

[40] T. N. Hayati, Rahman, J. Sunanto, and T. Y. Pratama, "The Assessment of Communication Ability on Deafblind Students," Adv. Sci. Lett., vol. 25, no. 1, pp. 126 129, 2019.

[41] K. Saddhono and M. Rohmadi, "A Sociolinguistics Study on the Use of the Javanese Language in the Learning Process in Primary Schools in Surakarta, Central Java, Indonesia." Int. Edu. Stu., vol. 7 no.6 pp 25-30, 2014 